\title{
Supporting Information on
}

\section{Anaerobic respiration in the unsaturated zone of agricultural soil mobilises phosphorus and manganese}

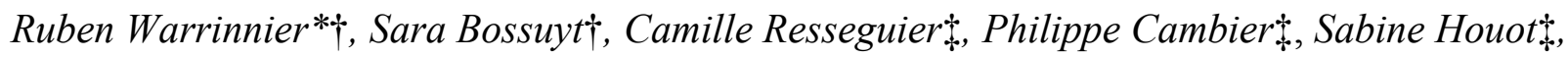
Jon Petter Gustafsson $\uparrow \dagger$, Jan Diels $\uparrow$ and Erik Smolders $\dagger$

$\dagger$ Division of Soil and Water Management, KU Leuven, Kasteelpark Arenberg, 20, B-3001

Leuven, Belgium.

+ UMR ECOSYS, INRA, AgroParisTech, Université Paris-Saclay, 78850 Thiverval-Grignon, France.

$\$ \dagger$ Department of Soil and Environment, Swedish University of Agricultural Sciences (SLU), Box 7014, 75007 Uppsala, Sweden.

27 pages, 8 figures, 8 tables. 
2 Section S1 The Qualiagro field experiment and wick samplers

Figure S1 Soil profile description, location of wick samplers and sampled soil layers.

Table S1 Summary statistics of wick sampler data.

Section S2 Test for potential oxidation during soil handling and $\mathrm{CaCl}_{2}$ extraction on field-moist soil.

Table S2 Mean properties of the sampled soils for the preliminary experiment, testing artificial oxidation upon soil sampling.

Figure S2 Concentration of $\mathrm{P}, \mathrm{Fe}$ and $\mathrm{Mn}$ in 'anoxic' and 'oxic' $1 \mathrm{mM} \mathrm{CaCl}_{2}$ extracts.

Section S3 P K-edge XANES spectroscopy: methods and results.

Figure S3 Stacked P K-edge XANES spectra (merged and normalized) for the ten analyzed soil samples.

Figure S4 Two examples of linear combination fits of P K-edge XANES spectra.

Table S3 Relative phosphorus speciation in soil samples (\%) as evidenced from the best fit obtained by linear combination fitting.

Section S4 Correction factor waterlogged soil incubations.

Table S4 Selected average soil properties of soil samples (all depths, all treatments).

Table S5 Correlation analyses of the variables measured in the wick samples.

Figure S5 The Fe and Mn concentration measured in the wick samples correlate negatively with those of $\mathrm{SO}_{4}{ }^{2-}$ and $\mathrm{NO}_{3}{ }^{-}$, both being electron acceptors.

Figure S6 In June 2016, large concentrations of Mn and P in the wick samples coincide with a high temperature and moisture content. The latter likely trigger reductive $\mathrm{P}$ release.

Table S6 Summary statistics of the soil properties.

Table S7 Correlation analyses soil properties.

Figure S7 Correlation between total 'dissolved' Fe(III) and $\mathrm{Al}(<0.45 \mu \mathrm{m})$ and Fe(III) and Al, and $\mathrm{Mn}$.

Figure S8 Total 'dissolved' Mn $(<0.45 \mu \mathrm{m})$ vs. truly dissolved Mn $(<12 \mathrm{kDa})$.

Table S8 Comparison between solutes measured in wicks and $\mathrm{CaCl}_{2}$ extracts. 
Section S1 The Qualiagro field experiment and wick samplers

31 Field experiment

32 The details of the field experiment have been described previously. ${ }^{1,2}$ In short, the experiment

33 started in 1998 in Feucherolles (Yvelines, France) on a Luvisol, a typical arable soil for the Paris

34 Basin. The experiment evaluates the agronomic value and environmental impact of different

35 organic amendments. Apart from the control treatment (mineral $\mathrm{N}$ fertilisers only; MIN N), four

36 different organic fertiliser treatments have been applied every two years on an equal carbon (C)

37 basis: an immature municipal solid waste compost (MSW), dairy farmyard manure (FYM) and

38 two more stable, less biodegradable composts (one from green waste and the source-separated

39 organic fraction of municipal waste, BIO, and a compost of green waste, wood chips and sewage

40 sludge, GWS). ${ }^{3}$ Chalhoub et al. (2013) report the characteristics of the applied amendments. ${ }^{4}$ In

411998 - 2013, application rates were equivalent to 4.0 ton organic C (OC) year ${ }^{-1}$ and since 2015

42 equivalent to 2.0 ton $\mathrm{OC}$ year ${ }^{-1}$ was applied. This resulted in large differences in net $\mathrm{P}$ balances,

43 i.e. $\mathrm{P}$ input via fertiliser application minus $\mathrm{P}$ export via grains and residues (Table S4). The

44 cumulative inputs (1998-2018) of $\mathrm{Fe}, \mathrm{Al}$ and $\mathrm{Mn}$ to the field via the fertiliser applications were

45 small in comparison to the oxalate extractable contents (i.e. less than $0.04 \%$ of the oxalate

46 extractable $\mathrm{Fe}$, less than $0.3 \%$ of the oxalate extractable $\mathrm{Al}$ and less than $6 \%$ of the oxalate

47 extractable $\mathrm{Mn}$ for all fertilisers).

48 Until 2014, cropping is done with a maize (Zea mays L.) - winter wheat (Triticum aestivum L.)

49 rotation. Winter barley (Hordeum vulgare L.) was grown in 2015, rye (Secale cereale L.) in 2016,

50 spring barley in 2017 and maize in 2018. The field plot sizes are 10 by $45 \mathrm{~m}$ and the trial has 4

51 treatment replicates. The description of the soil horizons of this silt loam Glossic Luvisol (FAO 
52 classification) is given in Figure S1.1,4 The plough layer (ca. $0-28 \mathrm{~cm}$; with an average bulk

53 density, $\rho_{\mathrm{b}}$, of $1320 \mathrm{~kg} \mathrm{~m}^{-3}$ ) covers a more compacted plough pan (ca. $28-35 \mathrm{~cm} ; \rho_{\mathrm{b}}=1490 \mathrm{~kg}$

$\left.54 \mathrm{~m}^{-3}\right)$. In the MIN N plot, temperature is recorded every hour at various depths $(1,5,10,15,20,40$,

$5560,80,100,130$ and $160 \mathrm{~cm}$ depth). The volumetric moisture content $\left(\theta_{\mathrm{v}}\right)$ is measured in all five

56 plots, six times a day, at different depths $(20,40,60,80,100,130,160 \mathrm{~cm}$ depth), using TDR

57 (Time-Domain Reflectometry) probes.

\section{Wick samplers}

60 Four wick samplers are installed in one field plot per treatment (two at 45 and two $100 \mathrm{~cm}$ depth)

61 since 2011 to collect percolating water (Figure S1)1. Cambier et al. (2014) detail the set-up of the

62 glass fibre wick samplers, temperature probes (between 1 and $160 \mathrm{~cm}$ depth), tensiometers and

63 TDR probes. From the autumn of 2012 until the present, during the drainage period, leachates are

64 collected in glass bottles, pumped out about twice a month, depending on the precipitation and

65 stored in PE-HD bottles at $4{ }^{\circ} \mathrm{C}$. The leached volume $(\mathrm{ml})$ is determined; samples are homogenized

66 and separated in aliquots for different analyses. The $\mathrm{pH}$ is measured on the same day or the day

67 after sampling. The concentrations of dissolved organic $\mathrm{C}$ (DOC), inorganic $\mathrm{C}$ (IC), nitrate $\left(\mathrm{NO}_{3}{ }^{-}\right.$

68 ), sulphate $\left(\mathrm{SO}_{4}^{2-}\right)$ and chloride $\left(\mathrm{Cl}^{-}\right)$were determined. Cations, phosphorus $(\mathrm{P})$ and silicon $(\mathrm{Si})$

69 were determined by ICP-OES and -MS (Inductively Coupled Plasma-Optical Emission

70 Spectroscopy and -Mass Spectroscopy; 2011-2017: LAS-INRA Arras, France; 2017-2018:

71 Agilent, Eindhoven, the Netherlands; 7700x). Limits of quantification (LOQ) can be found in

72 Table S2. For P, the LOQ varied along the years (2012-2013: $0.28 \mu \mathrm{M} ; 2014: 1.41 \mu \mathrm{M}$; 2015-

73 2017: $0.28 \mu \mathrm{M} ; 2018: 0.094 \mu \mathrm{M}$ ). The specific UV absorbance (SUVA), as an indicator for humic

74 substances, was measured as well. For details, see Cambier et al. (2014). ${ }^{1}$ 
75 Data were analysed using JMP PRO 13 SAS®. Data values below the limit of quantification 76 (LOQ) were set at LOQ divided by two (LOQ/2). Over the years, the LOQ of different variables

77 varied and all data points representing values below LOQ are shown in a light grey colour in the

78 figures of this paper. Correlation analyses were performed both with and without including these

79 values below LOQ. Prior to computing Pearson's product-moment correlation coefficients,

80 variables with a skewness coefficient larger than 1 were $\log _{10}$ transformed. It was visually checked

81 if a lognormal distribution better described the observed histograms and confirmed that the

82 skewness coefficients of all transformed distributions were reduced (Table S2). All skewness

83 coefficients of the transformed distributions are within the $[-1 ; 1]$ interval, except those of the

84 concentrations of manganese $(\mathrm{Mn})$, cadmium $(\mathrm{Cd})$, lead $(\mathrm{Pb}), \mathrm{Cl}^{-}$and aluminium (Al) (Table $\left.\mathrm{S} 2\right)$.

85 Two $\mathrm{pH}$ values and one SUVA value were detected as an outlier and were deleted. 
Sampled layers

\section{Profile description}

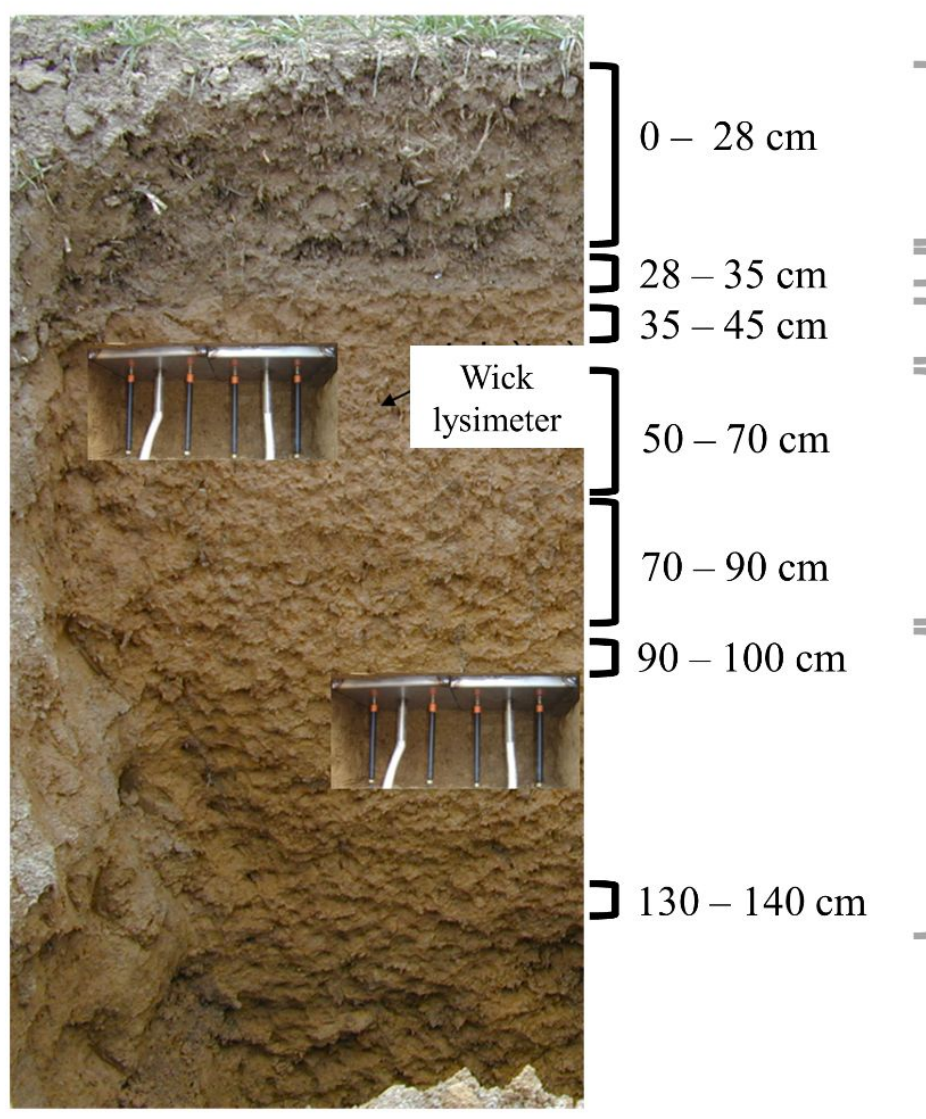

A: Plough layer; $0-28 \mathrm{~cm}$

A2: Plough pan; $28-35 \mathrm{~cm}$

E: Eluviated horizon; $35-50 \mathrm{~cm}$

Btgd: Illuviated horizon; mottling; $50-90 \mathrm{~cm}$

Bt/IC: Illuviated horizon; mixed with decarbonated loess; $90-140 \mathrm{~cm}$

88 Figure S1 Soil profile description ${ }^{1}$, location of wick samplers and sampled soil layers. 
91 Table S1 Summary statistics of wick sampler data. The limit of quantification (LOQ) for P ranged from 0.094 (in 2017-2018) to 1.41

$92 \mu \mathrm{M}$ (in 2013-2014). The LOQ for Fe ranged from 0.007 (in 2017-2018) to $18 \mu \mathrm{M}$ (in 2013-2014), for Mn from 0.001 to $0.018 \mu \mathrm{M}$.

\begin{tabular}{|c|c|c|c|c|c|c|c|c|c|}
\hline Variable & Period of measurement & $\mathbf{n}^{\mathbf{a}}$ & LOQ & $\#<\mathbf{L O Q}^{\mathbf{b}}$ & $\mathbf{P 1 0}$ & P50 ${ }^{c}$ & $\mathbf{P 9 0}^{\mathrm{c}}$ & Skewness & $\begin{array}{l}\text { Sk. after } \log _{10} \\
\text { transformation } \\
\end{array}$ \\
\hline $\begin{array}{l}\text { Leached volume } \\
\qquad\left(\mathrm{ml} \mathrm{cm}^{-2}\right)\end{array}$ & $2012-2017$ & 596 & / & 0 & 0.4 & 2.7 & 7.2 & 3.1 & -0.9 \\
\hline $\mathrm{pH}$ & $2012-2017$ & 593 & / & 0 & 7.3 & 7.6 & 7.9 & -0.1 & / \\
\hline SUVA $^{\mathrm{d}}$ & $2012-2016$ & 532 & / & 0 & 13 & 22 & 30 & 0.8 & l \\
\hline $\operatorname{DOC}^{f}(\mathrm{mg} / \mathrm{l})$ & $2012-2016$ & 534 & / & 0 & 5.4 & 10 & 20 & 1.2 & 0.0 \\
\hline$[\mathrm{Ca}]^{\mathrm{h}}(\mathrm{mM})$ & $2012-2018$ & 796 & 0.0012 & 0 & 1.2 & 2.3 & 4.0 & 1.7 & -0.3 \\
\hline$[\mathrm{K}](\mathrm{mM})$ & $2012-2017$ & 588 & 0.0025 & 2 & 0.01 & 0.10 & 0.72 & 2.4 & -0.2 \\
\hline$[\mathrm{Mg}](\mathrm{mM})$ & $2012-2017$ & 587 & 0.0008 & 0 & 0.18 & 0.36 & 0.7 & 1.6 & -0.2 \\
\hline$[\mathrm{Na}](\mathrm{mM})$ & $2012-2017$ & 587 & 0.004 & 0 & 0.40 & 1.1 & 3.2 & 3.3 & 0.1 \\
\hline$[\mathrm{Fe}](\mu \mathrm{M})$ & $2012-2018$ & 796 & $0.007-18$ & 495 & 0.07 & 1.8 & 9.0 & 16.0 & -0.6 \\
\hline$[\mathrm{P}](\mu \mathrm{M})$ & $2012-2018$ & 796 & $0.094-1.41$ & 373 & 0.14 & 0.52 & 1.8 & 8.6 & 0.6 \\
\hline$[\mathrm{Si}](\mathrm{mM})$ & $2012-2017$ & 587 & 0.001 & 0 & 0.22 & 0.53 & 0.93 & 0.8 & / \\
\hline$[\mathrm{Mn}](\mu \mathrm{M})$ & $2012-2018$ & 793 & $0.001-0.018$ & 355 & 0.005 & 0.009 & 0.114 & 10.0 & 1.5 \\
\hline$[\mathrm{Zn}](\mu \mathrm{M})$ & $2012-2017$ & 587 & 0.015 & 5 & 0.01 & 0.09 & 0.18 & 2.2 & -0.5 \\
\hline$[\mathrm{Cd}](\mu \mathrm{M})$ & $2012-2017$ & 587 & 0.0004 & 436 & 0.0002 & 0.0002 & 0.0010 & 4.0 & 1.8 \\
\hline$[\mathrm{Cu}](\mu \mathrm{M})$ & $2012-2017$ & 587 & 0.008 & 0 & 0.03 & 0.06 & 0.14 & 0.6 & -0.1 \\
\hline$[\mathrm{Ni}](\mu \mathrm{M})$ & $2012-2017$ & 587 & 0.017 & 105 & 0.009 & 0.033 & 0.066 & 1.5 & -0.4 \\
\hline$[\mathrm{Pb}](\mu \mathrm{M})$ & $2012-2017$ & 587 & 0.0005 & 316 & 0.0002 & 0.0002 & 0.0013 & 19.3 & 1.7 \\
\hline$[\mathrm{Cr}](\mu \mathrm{M})$ & $2012-2017$ & 586 & 0.02 & 298 & 0.01 & 0.01 & 0.04 & 5.7 & 0.7 \\
\hline$\left[\mathrm{Cl}^{-}\right](\mathrm{mM})$ & $2012-2013 ; 2015-2016$ & 326 & 0.008 & 12 & 0.03 & 0.61 & 2.11 & 1.6 & -1.1 \\
\hline$\left[\mathrm{SO}_{4}{ }^{2-}\right](\mathrm{mM})$ & $2012-2017$ & 589 & $0.0006-0.01$ & 0 & 0.03 & 0.26 & 1.65 & 4.9 & -0.2 \\
\hline$\left[\mathrm{NO}_{3}{ }^{-}\right](\mathrm{mM})$ & $2012-2017$ & 591 & $0.004-0.01$ & 0 & 0.01 & 0.76 & 3.55 & 3.5 & -0.7 \\
\hline$[\mathrm{IC}]^{\mathrm{g}}(\mathrm{mM})$ & $2012-2017$ & 533 & 1 & 0 & 1.84 & 3.31 & 5.82 & 1.2 & -0.1 \\
\hline$[\mathrm{Al}](\mu \mathrm{M})$ & $2017-2018$ & 209 & 0.1 & 43 & 0.07 & 0.25 & 1.85 & 6.8 & 1.5 \\
\hline
\end{tabular}

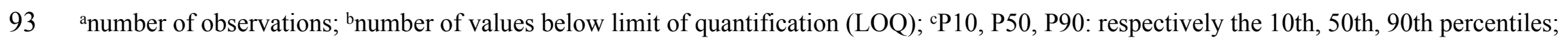

94 dSUVA: Specific UV absorbance; ' $S k e w n e s s$ coefficient after log transformation; ${ }^{\mathrm{f} D O C}$ : dissolved organic carbon; ${ }^{\mathrm{I} I C}$ : inorganic carbon; ${ }^{\text {h}}$ square 95 brackets indicate "concentration of". 

on field-moist soil.

\section{Conclusion}

100 This extra test showed that the 24 hours $\mathrm{CaCl}_{2}$ extraction of fresh soil (different soils as soils 101 from main manuscript, see below) in ambient conditions yielded less total 'dissolved' $\mathrm{P}$ and Fe $102(<0.45 \mu \mathrm{m})$ than a comparable extraction inside an anoxic glove box, i.e. confirming that some 103 oxidation reactions occur at ambient conditions.

106 On the one hand, as is explained in section 3.2 (main manuscript), artificial Mn reduction 107 during these 24 hours extractions can be excluded because the total 'dissolved' $\mathrm{Mn}$ concentrations $(<0.45 \mu \mathrm{m})$ peaked in the $28-35$ and $35-45 \mathrm{~cm}$ layers, not in the plough layers that have the largest $\mathrm{OC}$ content. Other influencing factors as $\mathrm{pH}$ and $\mathrm{Mn}$ oxyhydroxide content do not vary with depth. Thus, artificial Mn reduction would cause Mn to peak in the plough layer, which is not observed. Moreover, upon waterlogging these soils inside an anoxic glove box, Mn reduction started after two to six days of incubation (section 3.3), not within the first

11324 hours, as first oxygen and nitrates were consumed. On the other hand, this section showed 114 that the 24 hours $\mathrm{CaCl}_{2}$ extraction (on fresh soil) inside the anoxic glovebox extracted more $\mathrm{P}$ 115 that the extraction outside the glovebox. Thus, despite strongly confirming reductive $\mathrm{P}$ release

116 (see Results and Discussion in main manuscript), the $\mathrm{CaCl}_{2}$ extractions at ambient conditions 117 likely underestimate the reduced state of the in situ soil.

120 The objective was to test whether there is artificial oxidation of $\mathrm{Mn}$ (II, III) or Fe(II) during soil 121 handling (cold storage at $4{ }^{\circ} \mathrm{C}$ in plastic bags, max two weeks) and the $\mathrm{CaCl}_{2}$ extraction. Before extraction, the soil was shortly homogenized with a spatula. This induced artificial contact with air and might have triggered oxidation. Further artefacts might be induced by the large liquidsolid ratio (4 $1 \mathrm{~kg}^{-1}$ vs. an average in situ moisture content of $0.241 \mathrm{~kg}^{-1}$ ) because the $\mathrm{CaCl}_{2}$ solution was not deoxygenated (and thus in equilibrium with atmospheric $\mathrm{O}_{2}$ ). This brings a relatively large amount of oxygen in contact with a low amount of soil. The suspensions were centrifuged and filtered before acidification, which might introduce artefacts as well.

128 This was tested (on different soil samples than those of the main paper) by comparing identical extractions inside and outside an anoxic glove box, using normal $\mathrm{CaCl}_{2}$ solution outside the glove box and deoxygenated solution inside the box. The potential difference in the 
131 concentrations of $\mathrm{P}, \mathrm{Mn}, \mathrm{Fe}(\mathrm{II}), \mathrm{Fe}$ and $\mathrm{Al}$ in filtered $(0.45 \mu \mathrm{m})$ suspensions between the 'anoxic' (inside hood) and 'normal' (outside hood) treatments was assessed.

\section{Material and methods}

Different soils were sampled using a common soil auger (Table S2.1). On three locations, three cores were drilled (field replicates). Certain depths were sampled for each core (Table S2). For one of the three field replicates, analyses were performed in triplicate. The other two field replicates were analyzed without analytical replicates, resulting in a total of 26 samples. The soil samples were stored in vacuum-sealed plastic bags (Melissa replacement bags 16310181, vacuum, Skødstrup, Denmark), using a portable vacuum sealer (Melissa 16310179, Skødstrup, Denmark). Sealed bags were stored in an anoxic chamber (with an atmosphere consisting of $95 \% \mathrm{~N}_{2}$ and $5 \% \mathrm{H}_{2}$ and with platinum catalyzers converting any trace $\mathrm{O}_{2}$ to $\mathrm{H}_{2} \mathrm{O}$ ) for maximum two weeks.

Anoxic treatment Inside the anoxic chamber (Coy Laboratory Products, Grass Lake, United States), bags were opened, and $10 \mathrm{~g}$ fresh soil was extracted in deoxygenated $1 \mathrm{mM} \mathrm{CaCl} 2$ solution (overnight, bubbled with $\mathrm{N}_{2}$ gas under continuous stirring with a magnetic stirring rod and heated on a heating block $\left(105^{\circ} \mathrm{C}\right)$ ). The solid-liquid ratio was $0.25 \mathrm{~g} \mathrm{~L}^{-1}$. Pots, containing suspension, were mounted on a benchtop rotary shaker $\left(45^{\circ}\right.$ angle with horizontal; 11.5 rotations per minute). After 24 hours, suspension was filtered over $0.45 \mu \mathrm{m}$ (Chromafil ${ }^{\circledR}$ Xtra PET-45/25; Macherey-Nagel, Germany) and the filtrate was acidified using concentrated nitric acid (65\% $\mathrm{HNO}_{3}$; ultra-pure; Chem-Lab NV, Belgium) to a volume percentage of $1 \%$; prior to analysis of the concentrations of $\mathrm{P}, \mathrm{Fe}, \mathrm{Al}, \mathrm{Mn}$ and $\mathrm{Ca}$ by ICP-MS and ferrous Fe, Fe(II), by the ferrozine method ${ }^{5}$. The $\mathrm{pH}$ was measured in the settled suspensions. Filtration, acidification and $\mathrm{pH}$ measurement were preformed inside the anoxic chamber.

155 Oxic treatment Identical extractions were performed outside the chamber, with 'normal' $1 \mathrm{mM}$

$156 \mathrm{CaC}_{2}$ solution, as detailed in the main manuscript (without the centrifugation step to make the oxic and anoxic treatment comparable).

Data analysis The Limit of quantification (LOQ) for P was $0.15 \mu \mathrm{M}$ and for Fe(II) $0.52 \mu \mathrm{M}$. The $\mathrm{P}$ concentration of five samples was below LOQ. These points were set to half the LOQ and are indicated in grey in Figure S2. Moreover, they were not considered in the linear regression.

Results

164 The selected soils differ in P status, the degree of phosphate saturation (DPS) ranges from 0.02 165 to 0.69 (Table S2). Moreover, the organic carbon content (OC) ranges from 2 to $213 \mathrm{~g} \mathrm{C} \mathrm{kg}^{-1}$ 166 and the nitrogen content $(\mathrm{N})$ from 0.1 to $8.4 \mathrm{~g} \mathrm{~N} \mathrm{~kg}^{-1}$. The soils differ considerably from the 167 soils used in the main manuscript. Firstly, the $\mathrm{pH}$ is much lower, 4.8 (on average) here and 7.1 
168 (on average) in the soils from Qualiagro. Secondly, the average fraction of $\mathrm{Mn}$ in the total oxide

169 fraction is $0.45 \%$ as compared to $10 \%$ for the soils from Qualiagro.

170 The anoxic treatment gave a 2.3 times larger total 'dissolved' $(<0.45 \mu \mathrm{m}) \mathrm{P}$ concentration 171 than the oxic treatment, on average (95\% confidence interval is $[1.5 ; 3.1]$; Figure S2.1). The

172 red line represents the one-one line $\left([\mathrm{P}]_{\text {anoxic }}=[\mathrm{P}]_{\text {oxic }}\right)$ and the green line is the linear regression 173 line on a $\log -\log$ scale $\left(\log _{10}[\mathrm{P}]_{\text {anoxic }}=-0.02+1.2 \log _{10}[\mathrm{P}]_{\text {oxic }} ; \mathrm{R}^{2}=0.88\right)$. The green shade

174 shows the $95 \%$ confidence region of the fitted line, indicating that it differs significantly from 175 the one-one line, but only starting from $[\mathrm{P}]_{\text {oxic }}$ of $8.8 \mu \mathrm{mol} \mathrm{kg}{ }^{-1}$. Due to differences in the 176 moisture content of the fresh soil samples, concentrations in the filtered suspensions are 177 reported in mol kg-1 dry soil. Points in grey correspond to values that were below LOQ for [P] 178 in one or both treatments.

179 The difference between the P concentrations in both treatments is caused by Fe redox cycling, 180 not Mn redox cycling. The Fe concentrations for the anoxic treatment were about 1.7 orders of 181 magnitude larger than those of the oxic treatment $\left(\log _{10}[\mathrm{Fe}]_{\text {anoxic }}=1.7+0.9 \log _{10}[\mathrm{Fe}]_{\text {oxic }} ; \mathrm{R}^{2}=\right.$ 182 0.67). In contrast, the Mn concentrations do not differ significantly between both treatments. 183 Mn reduction precedes that of $\mathrm{Fe}$ upon waterlogging as more profound anoxia is needed for 184 the latter. ${ }^{6}$ Upon contact with oxygen, $\mathrm{Fe}^{2+}$ will oxidise before $\mathrm{Mn}^{2 / 3+}$ oxidation. The difference 185 in the concentrations of Fe in both treatments is thus caused by Fe redox cycling. The anoxic 186 treatment was in a reduced state with respect to Fe reduction and thus also $\mathrm{Mn}$ was in a reduced 187 state. As there is no difference between $\mathrm{Mn}$ in both treatments, Mn was in a reduced state as 188 well in the oxic treatments. To conclude, redox cycling caused a difference in the $\mathrm{P}$ 189 concentrations for both treatments. 
Table S2 Mean properties of the sampled soils for the experiment, testing artificial oxidation upon soil sampling and extraction.

\begin{tabular}{|c|c|c|c|c|c|c|c|c|c|c|c|}
\hline \multirow{2}{*}{ Location } & \multirow{2}{*}{ Depth } & \multirow{2}{*}{ pH } & \multirow{2}{*}{$\begin{array}{l}\text { Grav. moisture } \\
\text { content (-) }\end{array}$} & \multicolumn{4}{|c|}{ Oxalate extraction (mmol kg-1 $)$} & \multirow{2}{*}{$\begin{array}{c}\text { DPS } \\
(-)\end{array}$} & \multirow{2}{*}{$\begin{array}{c}\mathrm{OC} \\
\left(\mathrm{g} \mathrm{C} \mathrm{kg}^{-1}\right) \\
\end{array}$} & \multirow{2}{*}{$\begin{array}{c}\mathrm{N} \\
\left(\mathrm{g} \mathrm{N} \mathrm{kg}^{-1}\right)\end{array}$} & \multirow{2}{*}{$\begin{array}{c}\mathrm{C} / \mathrm{N} \\
\left(\mathrm{g} \mathrm{C}\left(\mathrm{g} \mathrm{N}^{-1}\right)\right.\end{array}$} \\
\hline & & & & $\mathbf{P}_{\text {Ox }}$ & $\mathbf{A l}_{\mathbf{O x}}$ & $\mathbf{F e}_{\mathbf{O x}}$ & $\mathbf{M n}_{O \mathbf{x}}$ & & & & \\
\hline $\mathrm{I}$ & $0-25$ & 5.2 & 0.05 & 3.8 & 21.5 & 6.2 & 0.28 & 0.27 & 13 & 0.7 & 19 \\
\hline I & $65-75$ & 4.8 & 0.06 & 2.8 & 30.2 & 2.8 & 0.02 & 0.17 & 4 & 0.2 & 20 \\
\hline II & $0-15$ & 3.5 & 3.59 & 3.6 & 94.0 & 292.6 & 0.2 & 0.02 & 213 & 8.4 & 25 \\
\hline II & $75-90$ & 4.6 & 0.38 & 0.4 & 15.6 & 5.8 & 0.02 & 0.04 & 11 & 0.4 & 28 \\
\hline III & $0-25$ & 5.6 & 0.13 & 9.5 & 20.7 & 6.6 & 0.3 & 0.69 & 16 & 0.9 & 18 \\
\hline III & $75-85$ & 5.4 & 0.13 & 0.5 & 11.3 & 3.5 & 0.1 & 0.07 & 2 & 0.1 & 17 \\
\hline
\end{tabular}

192

$[\mathrm{P}]$

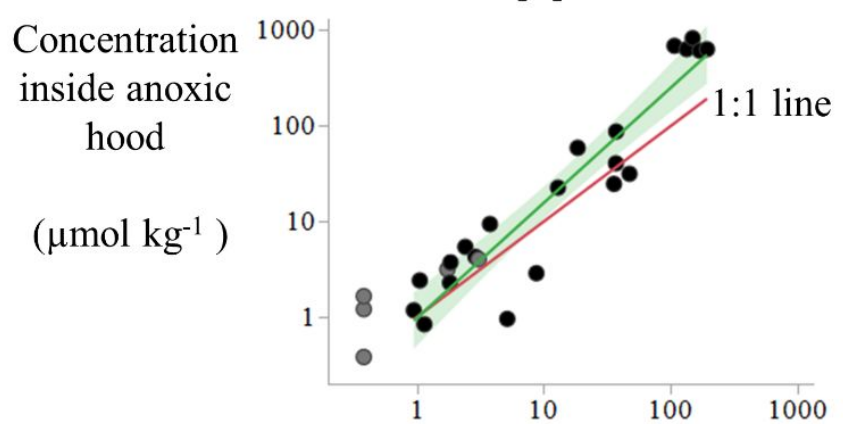

$[\mathrm{Fe}]$

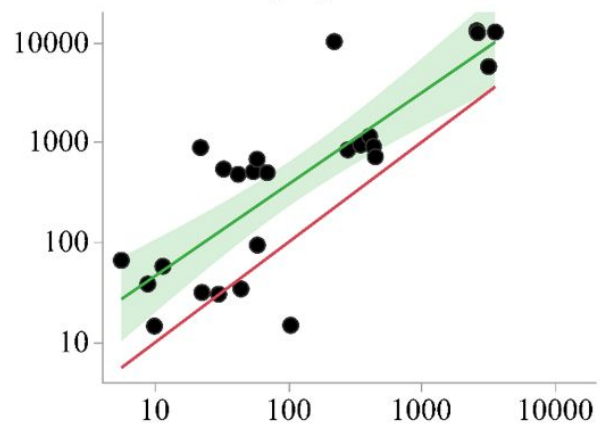

Concentration outside anoxic hood $(\mu \mathrm{mol} \mathrm{kg-1})$
$[\mathrm{Mn}]$

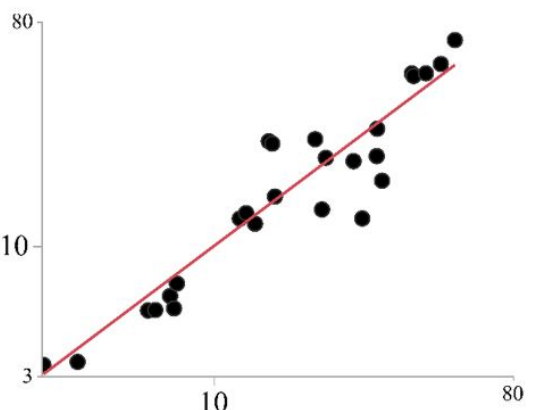

193

194 Figure $\mathbf{S 2}$ Concentration of $\mathrm{P}, \mathrm{Fe}$ and $\mathrm{Mn}$ in 'anoxic' and 'oxic' $1 \mathrm{mM} \mathrm{CaCl}_{2}$ extracts. The red lines represent the one-one line and the green lines are the linear regression line on a log-log scale. Green shades show the $95 \%$ confidence curve of the fitted line. Due to differences in moisture content of the fresh soil samples, concentrations in the filtered suspensions are reported in $\mathrm{mol} \mathrm{kg}^{-1}$ dry soil. Points in grey correspond to values that were below LOQ for $[\mathrm{P}]$ in one or both treatments. 
Methods

Before P K-edge XANES analysis, the air-dried soil samples from the $0-28 \mathrm{~cm}$ and $35-45 \mathrm{~cm}$ layers (composite sample from three field replicates) were milled and sieved to obtain a maximum particle size of $0.05 \mathrm{~mm}$. The P K-edge XANES spectra of the ten samples were collected in the same way as reported in previous research on beamline BL-8 of the Synchrotron Light Research Institute, Thailand. ${ }^{6-8}$ The beamline was equipped with an $\operatorname{InSb}(111)$ double crystal monochromator, giving a beam flux of $1.3 \times 10^{9}$ to $6 \times 10^{10}$ photons s$^{-1}(100 \mathrm{~mA})^{-1}$ in a $17.7 \times 0.9$ $\mathrm{mm}^{2}$ beam. ${ }^{7,8}$ Air in the sample compartment was replaced with $\mathrm{He}$ gas to avoid absorption of the incoming beam. The intensity of the incoming beam was determined with a $\mathrm{N}_{2}$-gas-filled ion chamber. Fluorescence measurements were carried out with a solid-state 13-element Ge detector. The measured fluorescence energy interval was $2100-2320 \mathrm{eV}$. The energy steps were smallest $(0.2 \mathrm{eV})$ close to the edge between 2140 and $2155 \mathrm{eV}$. In other energy ranges, the energy steps were up to $0.5 \mathrm{eV}$. The number of scans varied between 3 and 6 depending on the noise of the data.

214 Prior to the experiment, the beam energy was calibrated by setting the maximum of the first derivative of the spectrum $\left(\mathrm{E}_{0}\right)$ for elemental $\mathrm{P}$ powder (black phosphorus) to $2145.5 \mathrm{eV}$. Additionally XANES spectra of a variscite standard sample $\left(\mathrm{E}_{0}=2154.05 \mathrm{eV}\right)$ were regularly collected during the beamtime sessions. This was done to correct for errors in calibration and to detect unwanted energy shifts. Energy differences between $\mathrm{E}_{0}$ observed for the collected variscite spectra were used to correct $\mathrm{E}_{0}$ in sample spectra collected. ${ }^{7,8}$ Typically, corrections were within $\pm 0.15 \mathrm{eV}$ of the calibrated energy.

Multiple scans were merged and normalized in Athena, version 0.9.025. ${ }^{9}$ Generally, baseline correction was done by subtracting a linear function from the pre-edge region at $-30 \mathrm{eV}$ to $-10 \mathrm{eV}$ relative to $\mathrm{E}_{0}$ from the spectra. The edge step used for the normalisation was determined with a linear function across the post-edge region between $30 \mathrm{eV}$ and $45 \mathrm{eV}$ relative to $\mathrm{E}_{0 .}$. In a few cases, however, the normalisation energy range had to be slightly adjusted to deal with inconsistencies in baseline and background trends.

227 A set of spectra of known standards, measured at BL-8 in the same experimental conditions, ${ }^{7,8}$ was 228 combined to fit the sample spectra using an LCF (linear combination fitting) approach. ${ }^{10}$ The full 229 standard library, originally presented by Eriksson et al., 7,8 comprised 34 standards. Based on 230 preliminary runs with fitting one of the samples, and after an analysis of the uniqueness of each 231 standard for use as an endmember in LCF, a subset of 14 samples was selected as being the best 232 and most likely endmembers for the soils analyzed. These were: Taiba natural apatite, 
233 hydroxyapatite, brushite, octacalcium phosphate, amorphous $\mathrm{FePO}_{4}$, strengite, amorphous $\mathrm{AlPO}_{4}$,

234 variscite, $\mathrm{PO}_{4}$ adsorbed to ferrihydrite, $\mathrm{PO}_{4}$ adsorbed to goethite, $\mathrm{PO}_{4}$ adsorbed to amorphous $235 \mathrm{Al}(\mathrm{OH})_{3}, \mathrm{PO}_{4}$ adsorbed to gibbsite, $\mathrm{PO}_{4}$ adsorbed to allophane, and soil organic $\mathrm{P}$. Most of these 236 have been discussed in earlier publications. ${ }^{7-8}$ The soil organic $\mathrm{P}$ standard was from a Spodosol Oe 237 horizon at Paskalampa, central Sweden, which contained almost pure organic matter, with a very 238 low amount of extractable Fe and Al.

239 The LCF range was set from -10 to $+30 \mathrm{eV}$ relative to $\mathrm{E}_{0}$. Four standards were included in each 240 fit. Fits with weighting fractions summed to $100 \pm 10 \%$ were accepted. Accepted fits were then 241 renormalized to match a summed proportion of $100 \%$. The ranking of the accepted fits was based 242 on the $\mathrm{R}$ factor, as an indicator of the goodness-of-fit. 9,11

245 The merged and normalized P K-edge XANES spectra of all ten samples were almost identical 246 (Figure S3.1), showing that the overall $\mathrm{P}$ speciation was similar. For all samples, a pre-edge at 247 2149-2152 eV was clearly seen, showing that the contribution of Fe-bound P must be substantial. ${ }^{12}$ 248 Moreover, a weak post-edge shoulder at $2157.5 \mathrm{eV}$ (visible as a broadening of the white-line peak 249 on the high-energy side) and of a post-edge peak at $2164.7 \mathrm{eV}$ was just visible in some of the 250 samples, showing the presence of an apatite-type Ca phosphate mineral phase. For all samples 251 linear combination fitting revealed $\mathrm{PO}_{4}$ adsorbed to goethite to be the most likely Fe-bound $\mathrm{P}$ 252 phase (Figure $\mathrm{S} 3.2$ for two of the samples). This phase accounted for between 44 and $56 \%$ of all $253 \mathrm{P}$ in the samples, whereas the Ca-P content ranged from 16 to $36 \%$ of the $\mathrm{P}$ (Table S3.1). $\mathrm{PO}_{4}$ 254 adsorbed to $\mathrm{Al}$ oxyhydroxides and organic $\mathrm{P}$ were minor phases with between 9 and $24 \%$, and 255 between 0 and $13 \%$ of the $\mathrm{P}$, respectively. 


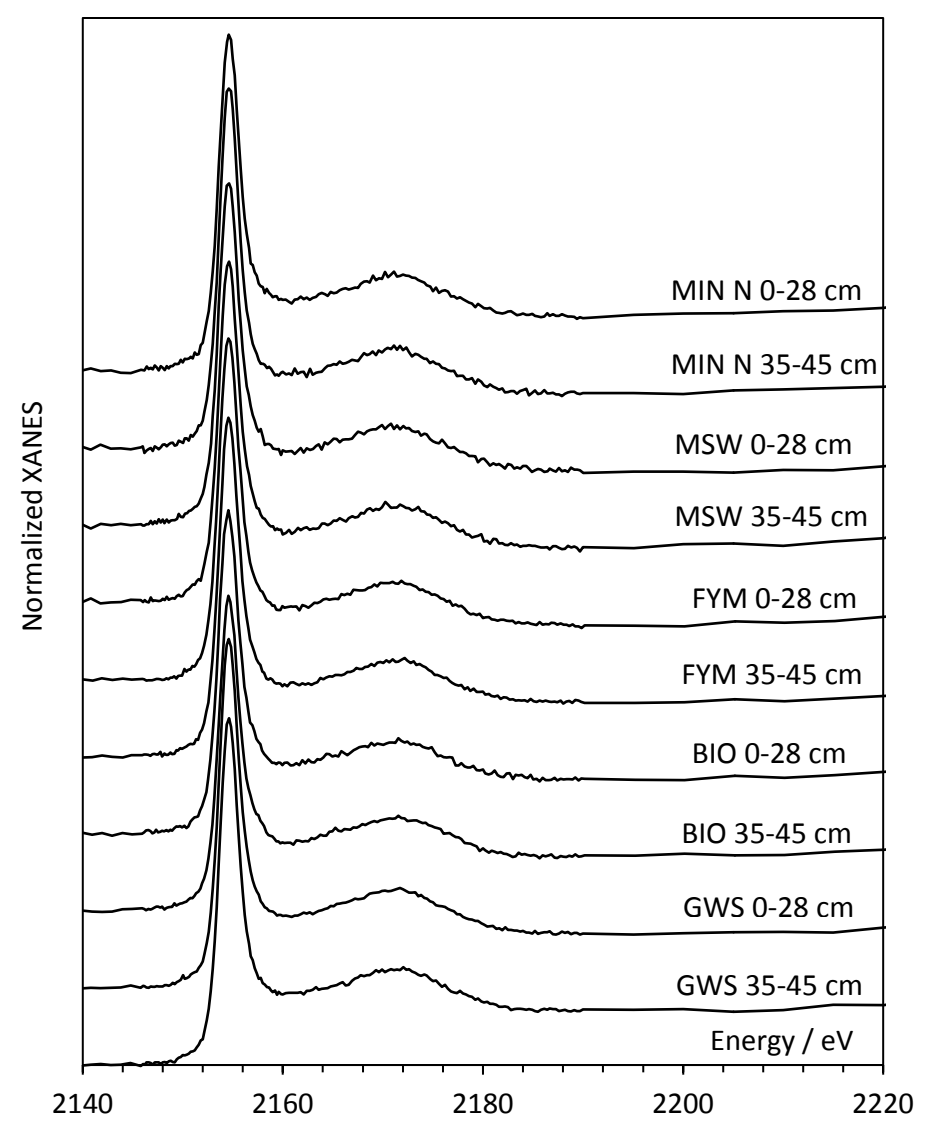

256 Figure S3 Stacked P K-edge XANES spectra (merged and normalized) for the ten analyzed 257 soil samples
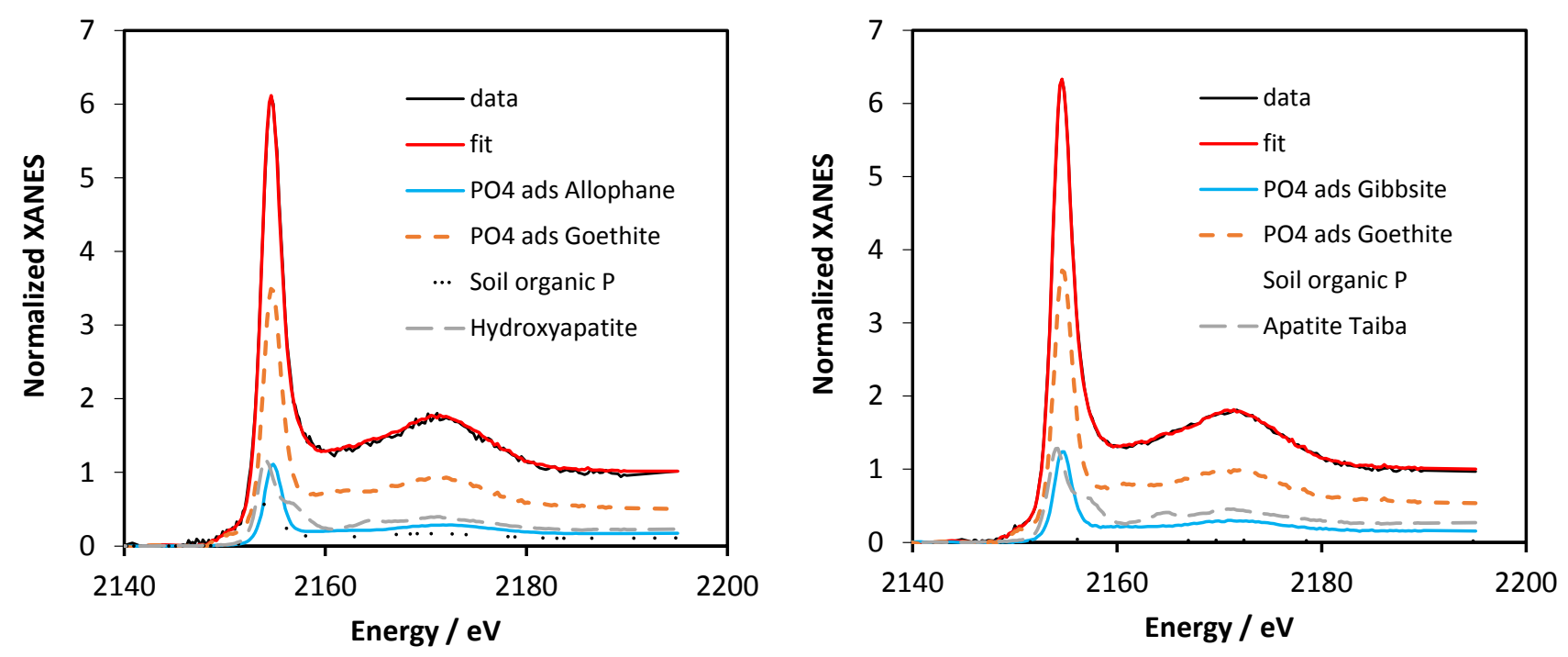

258 Figure S4 Two examples of linear combination fits of P K-edge XANES spectra. Left: MIN N 259 0-28 cm; right: GWS 0-28 cm 
260 Table S3 Relative phosphorus speciation in soil samples (\%) as evidenced from the best fit

261 obtained by linear combination fitting of XANES spectra. The uncertainties given are the

262 statistically based errors given by Athena. The five best fits are numbered from 1 to 5 in italics.

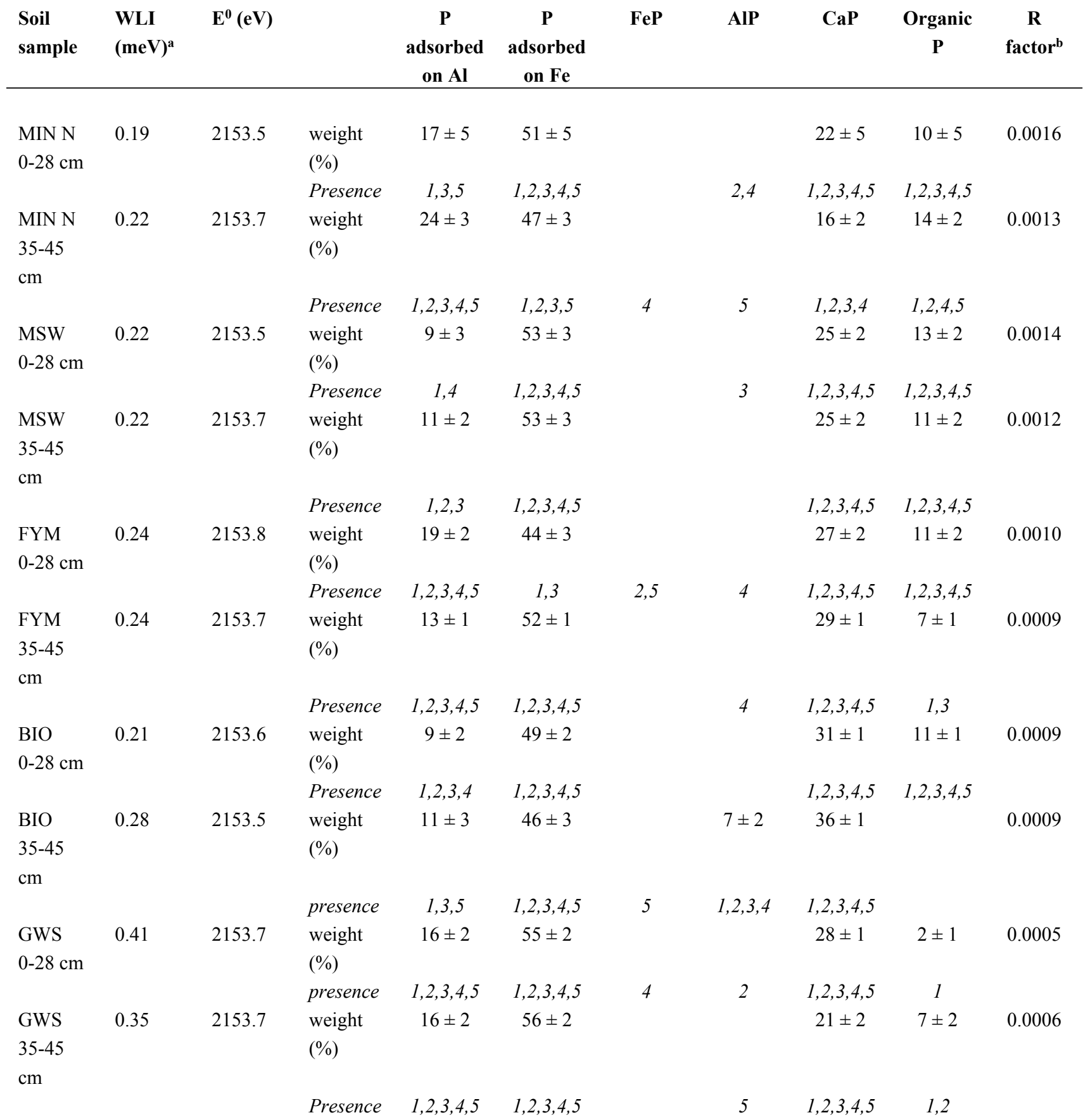

263 aWhite-line intensity ${ }^{8}$; ${ }^{b}$ Goodness-of-fit parameter given by Athena. ${ }^{11}$ 
267 At seven to eight time points, $18 \mathrm{ml}$ suspension was removed and replenished with fresh $\mathrm{CaCl}_{2}$ 268 solution, keeping the volume constant. Thus, at every sampling moment, part of the released P, Fe, $269 \mathrm{Al}$ and Mn were extracted from the suspensions. To account for this, a correction was applied to 270 the measured concentrations of each element at time point $\mathrm{i}\left([\mathrm{X}]_{\mathrm{m}, \mathrm{i}}\right)$.

$$
[X]_{c, i}=\frac{0.3[X]_{m, i}+0.018 \sum_{j=1}^{\mathrm{i}-1}[X]_{m, j}}{0.3}
$$

272 In the formula, $[\mathrm{X}]_{\mathrm{c}, \mathrm{i}}$ is the corrected concentration of element $\mathrm{X}$ at time $\mathrm{i}\left(\right.$ in $\left.\mathrm{mol} \mathrm{\textrm {l } ^ { - 1 }}\right)$. The total

273 volume is 0.31 and the sampled volume is 0.0181 . The sum of all moles lost in previous sampling

274 moments equals $0.018 \sum_{\mathrm{j}=1}^{\mathrm{i}-1}[\mathrm{X}]_{\mathrm{m}, \mathrm{j}}$. The determined concentrations of $\mathrm{P}, \mathrm{Al}, \mathrm{Fe}$ and Mn in the $0.45-$

$275 \mu \mathrm{m}$-filtered soil suspensions (84 in total) were all above the LOQ, except for that of $\mathrm{P}$ in 8 filtrates 276 from incubations of the 103-120 cm depth layer from FYM (LOQ was $0.4 \mu \mathrm{M}$ for P).

278 Dialysis experiment inside the anoxic glove box

279 The same correction was applied to the determined concentrations of truly dissolved elements $(<$ $28012 \mathrm{kDa}$ ) (recalculated to the concentration in the original soil suspension taking the dilution of the 281 dialysis step into account). More measured concentrations were below the LOQ here (P: 21 282 samples $<1.2 \mu \mathrm{M}$; Al: 32 samples $<0.9 \mu \mathrm{M}$; Mn: 20 samples $<0.02 \mu \mathrm{M}$; Fe: 11 samples $<0.73$ $283 \mu \mathrm{M})$. 
Table S4 The subsoil $(>28 \mathrm{~cm})$ is enriched with oxalate extractable P $\left(\mathrm{P}_{\mathrm{Ox}}\right)$. Significant differences in $\mathrm{P}_{\mathrm{Ox}}$ and the degree of phosphate saturation (DPS, $\mathrm{P}_{\mathrm{Ox}} / 0.5\left(\mathrm{Fe}_{\mathrm{Ox}}+\mathrm{Al}_{\mathrm{Ox}}\right)$ with the mineral $\mathrm{N}$ treatment $(\mathrm{MIN} \mathrm{N})$ at corresponding depth are shown in bold (Dunnet test, $\left.\mathrm{p}<0.05\right)$. The $35-45 \mathrm{~cm}$ depth layer of FYM is almost significantly enriched "**" ( $p=0.07$ for $\mathrm{P}_{\mathrm{Ox}}$ and $\mathrm{p}=0.06$ for DPS), in contrast to that of $\mathrm{BIO}(\mathrm{p}=0.15$ and 0.17$)$. The $\mathrm{P}$ balance was calculated from recorded

287 P applications and crop P offtake with exported grains and residues.

\begin{tabular}{|c|c|c|c|c|c|c|c|c|c|c|c|c|c|c|}
\hline \multirow{2}{*}{ Treatment } & \multirow{2}{*}{$\begin{array}{c}\mathbf{P} \\
\text { balance } \\
(\mathbf{k g ~ P} \\
\text { ha }^{-1} \\
\left.\text { year }^{-1}\right) \\
\end{array}$} & \multirow{2}{*}{$\begin{array}{c}\text { Depth } \\
\text { (cm) }\end{array}$} & \multicolumn{4}{|c|}{ Oxalate extraction $\left(\mathrm{mmol} \mathrm{kg}^{-1}\right)$} & \multirow{2}{*}{$\begin{array}{c}\text { DPS }^{*} \\
(-)\end{array}$} & \multirow{2}{*}{$\begin{array}{c}\mathrm{OC} \\
\left(\mathrm{g} \mathrm{C} \mathrm{kg}^{-1}\right)\end{array}$} & \multirow{2}{*}{$\begin{array}{c}\mathrm{N} \\
(\mathrm{g} \mathrm{N} \mathrm{kg})\end{array}$} & \multicolumn{5}{|c|}{ P-XANES (weight \%) } \\
\hline & & & $\mathbf{P}_{\text {Ox }}$ & $\mathrm{Fe}_{\mathrm{Ox}}$ & $\mathbf{A l}_{\mathbf{O x}}$ & $\mathbf{M n}_{\text {Ox }}$ & & & & $P$ adsorbed on Al & $P$ adsorbed on $\mathrm{Fe}$ & AIP & $\mathrm{CaP}$ & Organic $\mathbf{P}$ \\
\hline \multirow{7}{*}{ MIN N } & \multirow{7}{*}{-23} & $0-28$ & 7.9 & 52 & 22 & 6.9 & 0.21 & 8 & 1.0 & 17 & 51 & 0 & 22 & 10 \\
\hline & & $28-35$ & 5.5 & 53 & 29 & 7.7 & 0.14 & 7 & 0.9 & & & & & \\
\hline & & $35-45$ & 5.5 & 52 & 33 & 4.5 & 0.13 & 6 & 0.8 & 24 & 47 & 0 & 16 & 14 \\
\hline & & $50-70$ & 4.1 & 49 & 40 & 2.7 & 0.09 & 3 & 0.6 & & & & & \\
\hline & & $70-90$ & 4.1 & 40 & 32 & 4.8 & 0.12 & 2 & 0.5 & & & & & \\
\hline & & $90-100$ & 5.3 & 42 & 30 & 5.2 & 0.15 & 2 & 0.5 & & & & & \\
\hline & & $130-140$ & 4.9 & 34 & 26 & 6.0 & 0.16 & 1 & 0.4 & & & & & \\
\hline \multirow{7}{*}{ MSW } & \multirow{7}{*}{-2.8} & $0-28$ & 7.9 & 52 & 21 & 7.0 & 0.22 & 11 & 1.2 & 9 & 53 & 0 & 25 & 13 \\
\hline & & $28-35$ & 7.6 & 50 & 20 & 7.0 & 0.22 & 10 & 1.2 & & & & & \\
\hline & & $35-45$ & 6.0 & 57 & 31 & 5.7 & 0.14 & 9 & 1.1 & 11 & 53 & 0 & 25 & 11 \\
\hline & & $50-70$ & 5.3 & 64 & 32 & 7.3 & 0.11 & 4 & 0.6 & & & & & \\
\hline & & $70-90$ & 4.6 & 62 & 42 & 5.8 & 0.09 & 3 & 0.7 & & & & & \\
\hline & & $90-100$ & 4.8 & 44 & 34 & 7.8 & 0.13 & 2 & 0.5 & & & & & \\
\hline & & $130-140$ & 6.8 & 45 & 26 & 6.2 & 0.19 & 1 & 0.4 & & & & & \\
\hline \multirow{7}{*}{ FYM } & \multirow{7}{*}{11} & $0-28$ & 10.1 & 50 & 20 & 7.6 & 0.29 & 11 & 1.3 & 19 & 44 & 0 & 27 & 11 \\
\hline & & $28-35$ & 10.0 & 48 & 20 & 7.7 & 0.29 & 12 & 1.3 & & & & & \\
\hline & & $35-45$ & $9.8^{*}$ & 49 & 19 & 7.4 & $0.29 *$ & 10 & 1.1 & 13 & 52 & 0 & 29 & 7 \\
\hline & & $50-70$ & 5.6 & 56 & 28 & 7.2 & 0.13 & 4 & 0.7 & & & & & \\
\hline & & $70-90$ & 4.2 & 49 & 37 & 5.9 & 0.10 & 3 & 0.5 & & & & & \\
\hline & & $90-100$ & 3.9 & 46 & 42 & 3.5 & 0.09 & 3 & 0.5 & & & & & \\
\hline & & $130-140$ & 4.0 & 30 & 32 & 7.5 & 0.13 & 1 & 0.4 & & & & & \\
\hline \multirow{7}{*}{$\mathrm{BIO}$} & \multirow{7}{*}{20} & $0-28$ & 9.5 & 52 & 21 & 7.3 & 0.26 & 14 & 1.5 & 9 & 49 & 0 & 31 & 11 \\
\hline & & $28-35$ & 9.4 & 53 & 23 & 7.5 & 0.25 & 12 & 1.3 & & & & & \\
\hline & & $35-45$ & 8.7 & 53 & 22 & 7.0 & 0.23 & 9 & 1.0 & 11 & 46 & 7 & 36 & 0 \\
\hline & & $50-70$ & 5.7 & 67 & 33 & 7.4 & 0.11 & 4 & 0.6 & & & & & \\
\hline & & $70-90$ & 5.1 & 69 & 40 & 7.6 & 0.09 & 3 & 0.6 & & & & & \\
\hline & & $90-100$ & 4.7 & 54 & 48 & 6.6 & 0.09 & 2 & 0.5 & & & & & \\
\hline & & $130-140$ & 4.4 & 35 & 33 & 5.7 & 0.13 & 1 & 0.4 & & & & & \\
\hline \multirow{7}{*}{ GWS } & \multirow{7}{*}{85} & $0-28$ & 20.4 & 61 & 29 & 7.3 & 0.45 & 15 & 1.6 & 16 & 55 & 0 & 28 & 2 \\
\hline & & $28-35$ & 18.1 & 59 & 27 & 7.1 & 0.42 & 15 & 1.6 & & & & & \\
\hline & & $35-45$ & 13.9 & 61 & 27 & 7.3 & 0.32 & 10 & 1.1 & 16 & 56 & 0 & 21 & 7 \\
\hline & & $50-70$ & 7.5 & 68 & 31 & 6.4 & 0.15 & 6 & 0.8 & & & & & \\
\hline & & $70-90$ & 6.1 & 72 & 38 & 8.1 & 0.11 & 3 & 0.5 & & & & & \\
\hline & & $90-100$ & 6.2 & 69 & 40 & 8.6 & 0.11 & 2 & 0.5 & & & & & \\
\hline & & $130-140$ & 5.4 & 43 & 35 & 3.8 & 0.14 & 1 & 0.3 & & & & & \\
\hline
\end{tabular}


289 Table S5 Correlation analysis of the variables measured in the wick leachate samples reveals 290 associations between the concentration of P ([P]), Mn and Fe. Coefficients in bold show the 291 strongest correlations.

\section{Pearson product-moment correlations with $\log [\mathrm{P}]$ \\ $<$ LOQ set to LOQ/2 $<$ LOQ removed}

\begin{tabular}{|c|c|c|c|c|c|c|}
\hline Variable & $\mathbf{n}$ & $\#<\mathbf{L O Q}$ & Cor. coefficient & $P$ value & Cor. coefficient & $P$ value \\
\hline Log(water volume) & 596 & 0 & -0.18 & $<0.0001$ & -0.10 & 0.3 \\
\hline $\mathrm{pH}$ & 593 & 0 & +0.16 & 0.0002 & +0.13 & 0.06 \\
\hline SUVA & 532 & 0 & +0.28 & $<0.0001$ & +0.10 & 0.002 \\
\hline LogDOC & 534 & 0 & +0.07 & 0.04 & +0.20 & 0.66 \\
\hline $\log [\mathrm{Ca}]$ & 796 & 0 & -0.20 & $<0.0001$ & -0.06 & 0.22 \\
\hline $\log [\mathrm{K}]$ & 588 & 2 & +0.29 & $<0.0001$ & +0.30 & $<0.0001$ \\
\hline $\log [\mathrm{Mg}]$ & 587 & 0 & +0.02 & 0.41 & +0.27 & 0.001 \\
\hline $\log [\mathrm{Na}]$ & 587 & 0 & +0.19 & $<0.0001$ & +0.31 & 0.004 \\
\hline $\log [\mathrm{Fe}]$ & 796 & 495 & +0.03 & 0.41 & $+\mathbf{0 . 5 7}$ & $<0.0001$ \\
\hline$[\mathrm{Si}]$ & 587 & 0 & +0.26 & $<0.0001$ & +0.27 & $<0.0001$ \\
\hline $\log [\mathrm{Mn}]$ & 793 & 355 & +0.43 & $<0.0001$ & $+\mathbf{0 . 5 0}$ & $<0.0001$ \\
\hline $\log [\mathrm{Zn}]$ & 587 & 5 & +0.06 & 0.16 & +0.01 & 0.6 \\
\hline $\log [\mathrm{Cd}]$ & 587 & 436 & +0.07 & 0.11 & -0.17 & 0.2 \\
\hline $\log [\mathrm{Cu}]$ & 587 & 0 & +0.18 & $<0.0001$ & +0.20 & 0.002 \\
\hline $\log [\mathrm{Ni}]$ & 587 & 105 & +0.18 & 0.0009 & +0.19 & 0.007 \\
\hline $\log [\mathrm{Pb}]$ & 587 & 316 & +0.07 & 0.07 & +0.23 & 0.03 \\
\hline $\log [\mathrm{Cr}]$ & 586 & 298 & +0.18 & $<0.0001$ & +0.42 & $<0.0001$ \\
\hline $\log \left[\mathrm{Cl}^{-}\right]$ & 326 & 12 & -0.34 & $<0.0001$ & -0.11 & 0.3 \\
\hline $\log \left[\mathrm{SO}_{4}{ }^{2-}\right]$ & 589 & 0 & -0.13 & 0.02 & -0.05 & 0.3 \\
\hline $\log \left[\mathrm{NO}_{3}{ }^{-}\right]$ & 591 & 0 & -0.14 & 0.009 & +0.08 & 0.4 \\
\hline $\log [\mathrm{IC}]$ & 533 & 0 & +0.26 & $<0.0001$ & +0.25 & 0.0003 \\
\hline $\log [\mathrm{Al}]$ & 209 & 43 & +0.43 & $<0.0001$ & +0.47 & $<0.0001$ \\
\hline
\end{tabular}



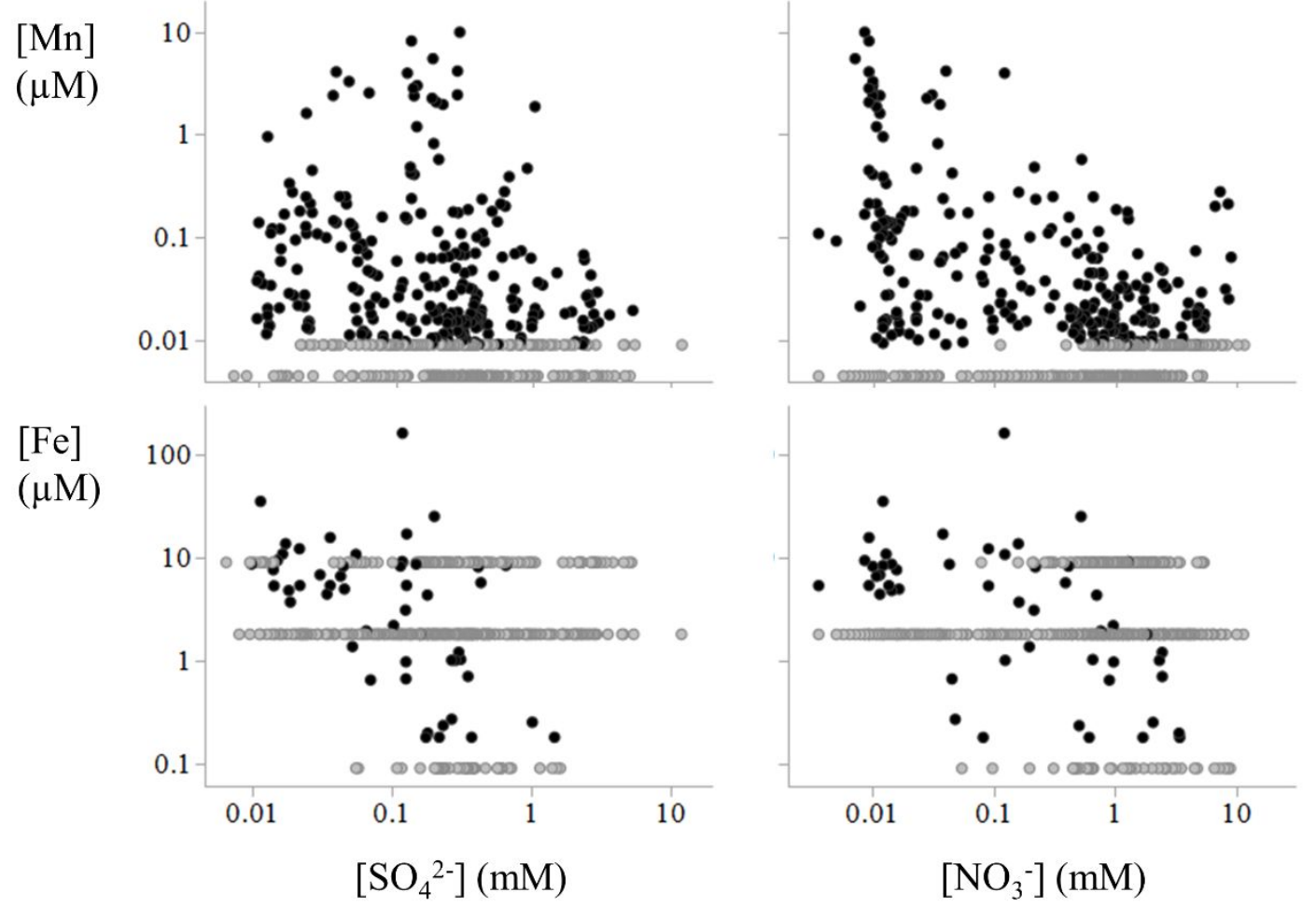

294 Figure S5 The Fe and Mn concentration ([Fe] and $[\mathrm{Mn}]$ ) measured in the wick samples, correlates negatively with those of SO${ }_{4}^{2-}$ and $295 \mathrm{NO}_{3}{ }^{-}$, both being electron acceptors. Data below the limit of quantification (LOQ) are in grey. $\mathrm{Mn}_{\mathrm{vs}} \mathrm{SO}_{4}: \mathrm{All}$ data: $\mathrm{r}=-0.25 ; \mathrm{p}<$ 296 0.0001; Without values < LOQ: $\mathrm{r}=-0.20$; $\mathrm{p}$ 0.0018; Mn vs. $\mathrm{NO}_{3}$ : All data: $\mathrm{r}=-0.39 ; \mathrm{p}<0.0001$; Without values < LOQ: $\mathrm{r}=-0.47$; $\mathrm{p}<$ 297 0.0001; Fe vs. SO $\mathrm{SO}_{4}$ All data: $\mathrm{r}=-0.08 ; \mathrm{p}=0.05 ;$ Without values $<$ LOQ: $\mathrm{r}=-0.54 ; \mathrm{p}<0.0001 ; \mathrm{Fe}$ vs. $\mathrm{NO}_{3}$ : All data: $\mathrm{r}=-0.04 ; \mathrm{p}=$ 298 0.31; Without values $<$ LOQ: $\mathrm{r}=-0.55$; $\mathrm{p}<0.0001$. 


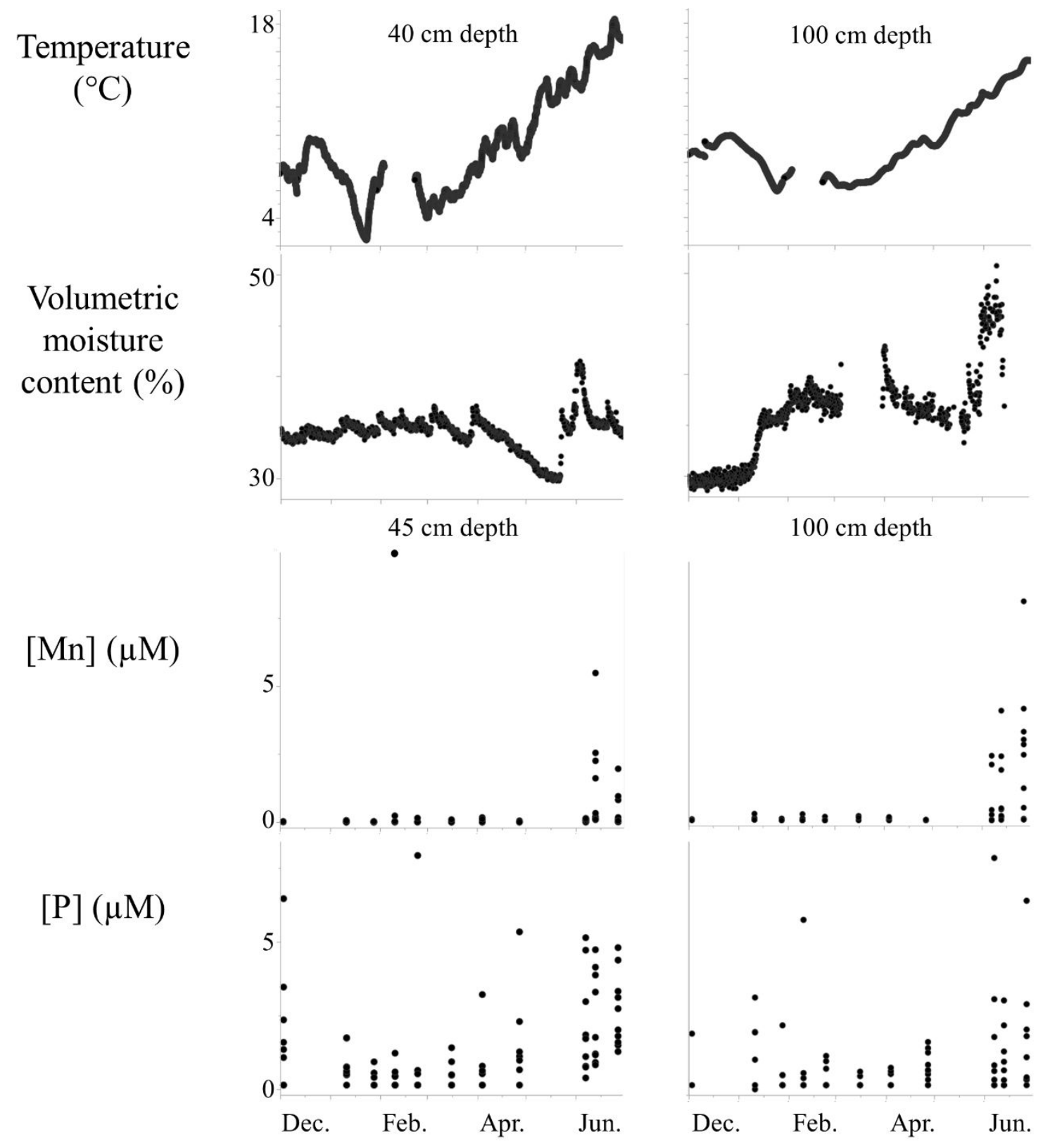

300 Figure S6 In June 2016, large concentrations of Mn and P in the wick samples coincide with a 301 high temperature and moisture content. The latter likely trigger reductive $\mathrm{P}$ release. The 302 temperature was measured in the MIN N plot. Only the volumetric moisture content in the plot 303 amended with compost of green waste, woodchips and sewage sludge (GWS) is shown, but the 304 other plots show an identical pattern. The concentrations of $\mathrm{Mn}$ and $\mathrm{P}$ are shown for all plots. 
305 Table S6 Summary statistics of the soil properties (all treatments and depths combined, variables in square brackets are concentrations

306 of the filtered $(0.45 \mu \mathrm{m}) 1 \mathrm{mM} \mathrm{CaCl}_{2}$ extracts of field moist soils).

\begin{tabular}{|c|c|c|c|c|c|c|c|}
\hline Variable & $\mathbf{n}$ & $\begin{array}{c}\#< \\
\text { LOQ }\end{array}$ & P10 & P50 & P90 & Skewness & $\begin{array}{l}\text { Sk. after } \log _{10} \\
\text { transformation }\end{array}$ \\
\hline $\mathrm{pH}$ & 105 & 0 & 6.7 & 7.1 & 7.4 & -0.14 & \\
\hline$[\mathrm{Fe}(\mathrm{II})](\mu \mathrm{M})$ & 105 & 90 & 0.26 & 0.26 & 1.1 & 7.2 & 2.9 \\
\hline$[\mathrm{P}](\mu \mathrm{M})$ & 105 & 2 & 0.21 & 1.7 & 23 & 1.8 & 0.1 \\
\hline$[\mathrm{Fe}(\mathrm{III})](\mu \mathrm{M})$ & 105 & 0 & 3.4 & 16 & 34 & 1.8 & -0.59 \\
\hline$[\mathrm{Al}](\mu \mathrm{M})$ & 105 & 0 & 10 & 44 & 77 & 2.8 & -0.57 \\
\hline$[\mathrm{Mn}](\mu \mathrm{M})$ & 105 & 0 & 0.02 & 0.24 & 1.4 & 3 & -0.03 \\
\hline$[\mathrm{Ca}](\mathrm{mM})$ & 105 & 0 & 0.97 & 1.1 & 1.3 & 0.73 & \\
\hline $\begin{array}{c}\text { Water filled porosity, } \\
\text { WFP (-) }\end{array}$ & 105 & 0 & 0.80 & 0.91 & 1.0 & 0.77 & \\
\hline $\mathrm{P}_{\mathrm{Ox}}\left(\mathrm{mmol} \mathrm{kg}{ }^{-1}\right)$ & 105 & 0 & 3.9 & 5.9 & 10 & 2.1 & 0.81 \\
\hline $\mathrm{Fe}_{\mathrm{Ox}}\left(\mathrm{mmol} \mathrm{kg}{ }^{-1}\right)$ & 105 & 0 & 34 & 53 & 67 & -0.12 & \\
\hline $\mathrm{Al}_{\mathrm{Ox}}\left(\mathrm{mmol} \mathrm{kg} \mathrm{kg}^{-1}\right)$ & 105 & 0 & 20 & 30 & 43 & 0.35 & \\
\hline $\mathrm{Mn}_{\mathrm{Ox}}\left(\mathrm{mmol} \mathrm{kg}{ }^{-1}\right)$ & 105 & 0 & 3.7 & 6.7 & 8.7 & -0.04 & \\
\hline DPS (-) & 105 & 0 & 0.09 & 0.14 & 0.31 & 1.3 & 0.44 \\
\hline $\mathrm{N}\left(\mathrm{g} \mathrm{N} \mathrm{kg}^{-1}\right)$ & 105 & 0 & 0.4 & 0.6 & 1.3 & 0.73 & \\
\hline $\mathrm{OC}\left(\mathrm{g} \mathrm{C} \mathrm{kg}^{-1}\right)$ & 105 & 0 & 1.4 & 4.0 & 12 & 0.67 & \\
\hline
\end{tabular}

307 DPS: Degree of phosphate saturation, calculated as $\mathrm{P}_{\mathrm{Ox}} / 0.5\left(\mathrm{Fe}_{\mathrm{Ox}}+\mathrm{Al}_{\mathrm{Ox}}\right)$. 
308 Table S7 Pearson product-moment correlation coefficients of the soil properties (all locations and depths combined, variables in square brackets 309 are concentrations of the filtered $(0.45 \mu \mathrm{m}) 1 \mathrm{mM} \mathrm{CaCl} 2$ extracts with field moist soils). Most strong correlations are shown in bold (except if 310 trivial).

\begin{tabular}{|c|c|c|c|c|c|c|c|c|c|c|}
\hline \multirow{3}{*}{ Variable } & \multirow{2}{*}{\multicolumn{2}{|c|}{$\log _{10}[\mathbf{P}]$}} & \multirow{2}{*}{\multicolumn{2}{|c|}{$\log _{10}[M n]$}} & \multirow{2}{*}{\multicolumn{2}{|c|}{$\log _{10}[\mathrm{Fe}(\mathrm{III})+\mathrm{Al}]$}} & \multicolumn{4}{|c|}{$\log _{10}[\mathrm{Fe}(\mathrm{II})]$} \\
\hline & & & & & & & \multicolumn{2}{|c|}{ with $<$ LOQ } & \multicolumn{2}{|c|}{ without $<$ LOQ } \\
\hline & $\mathrm{r}$ & $\mathrm{p}$ value & $\mathrm{r}$ & $\mathrm{p}$ value & $\mathrm{r}$ & $\mathrm{p}$ value & $\mathrm{r}$ & $\mathrm{p}$ value & $\mathrm{r}$ & $\mathrm{p}$ value \\
\hline Water-filled porosity & -0.28 & 0.004 & -0.21 & 0.03 & -0.26 & 0.007 & +0.12 & 0.2 & -0.15 & 0.6 \\
\hline $\mathrm{pH}$ & -0.03 & 0.7 & +0.02 & 0.82 & +0.14 & 0.2 & +0.02 & 0.9 & +0.12 & 0.7 \\
\hline $\mathrm{OC}\left(\mathrm{g} \mathrm{C} \mathrm{kg}^{-1}\right)$ & +0.92 & $<0.0001$ & +0.83 & $<0.0001$ & +0.61 & $<0.0001$ & +0.09 & 0.4 & +0.05 & 0.8 \\
\hline $\mathrm{N}\left(\mathrm{g} \mathrm{N} \mathrm{kg}^{-1}\right)$ & +0.90 & $<0.0001$ & +0.82 & $<0.0001$ & +0.60 & $<0.0001$ & +0.09 & 0.4 & +0.03 & 0.9 \\
\hline $\log _{10}\left(\mathrm{P}_{\mathrm{Ox}}, \mathrm{mmol} \mathrm{kg}^{-1}\right)$ & +0.78 & $<0.0001$ & +0.65 & $<0.0001$ & +0.43 & $<0.0001$ & +0.04 & 0.7 & +0.04 & 0.9 \\
\hline $\mathrm{Fe}_{\mathrm{Ox}}\left(\mathrm{mmol} \mathrm{kg}{ }^{-1}\right)$ & +0.24 & 0.014 & +0.24 & 0.01 & +0.21 & 0.03 & -0.05 & 0.6 & +0.34 & 0.2 \\
\hline $\mathrm{Al}_{\mathrm{Ox}}\left(\mathrm{mmol} \mathrm{kg}{ }^{-1}\right)$ & -0.60 & $<0.0001$ & -0.59 & $<0.0001$ & -0.43 & $<0.0001$ & -0.14 & 0.2 & -0.25 & 0.4 \\
\hline $\mathrm{Mn}_{\mathrm{Ox}}\left(\mathrm{mmol} \mathrm{kg}{ }^{-1}\right)$ & +0.28 & 0.004 & +0.26 & 0.01 & +0.20 & 0.04 & +0.01 & 0.9 & +0.32 & 0.2 \\
\hline $\log _{10} \operatorname{DPS}(-)$ & +0.75 & $<0.0001$ & +0.62 & $<0.0001$ & +0.40 & $<0.0001$ & +0.08 & 0.4 & 0.00 & 1.0 \\
\hline $\log _{10}([\mathrm{P}], \mu \mathrm{M})$ & +1.00 & $<0.0001$ & +0.95 & $<0.0001$ & +0.80 & $<0.0001$ & +0.19 & 0.05 & +0.31 & 0.3 \\
\hline $\log _{10}([\mathrm{Mn}], \mu \mathrm{M})$ & +0.95 & $<0.0001$ & 1.00 & $<0.0001$ & +0.89 & $<0.0001$ & +0.27 & 0.006 & +0.35 & 0.2 \\
\hline $\log _{10}([\mathrm{Fe}(\mathrm{II})], \mu \mathrm{M})$ & +0.19 & 0.052 & +0.27 & 0.01 & +0.22 & 0.022 & +1.00 & $<0.0001$ & 1.00 & $<0.0001$ \\
\hline $\log _{10}([\mathrm{Fe}(\mathrm{III})], \mu \mathrm{M})$ & +0.82 & $<0.0001$ & +0.88 & $<0.0001$ & +0.98 & $<0.0001$ & +0.22 & 0.03 & +0.19 & 0.5 \\
\hline $\log _{10}([\mathrm{Al}], \mu \mathrm{M})$ & +0.79 & $<0.0001$ & +0.88 & $<0.0001$ & +1.00 & $<0.0001$ & +0.22 & 0.02 & +0.39 & 0.2 \\
\hline$[\mathrm{Ca}](\mu \mathrm{M})$ & +0.57 & $<0.0001$ & +0.52 & $<0.0001$ & 0.27 & 0.006 & -0.06 & 0.5 & +0.02 & 0.9 \\
\hline
\end{tabular}



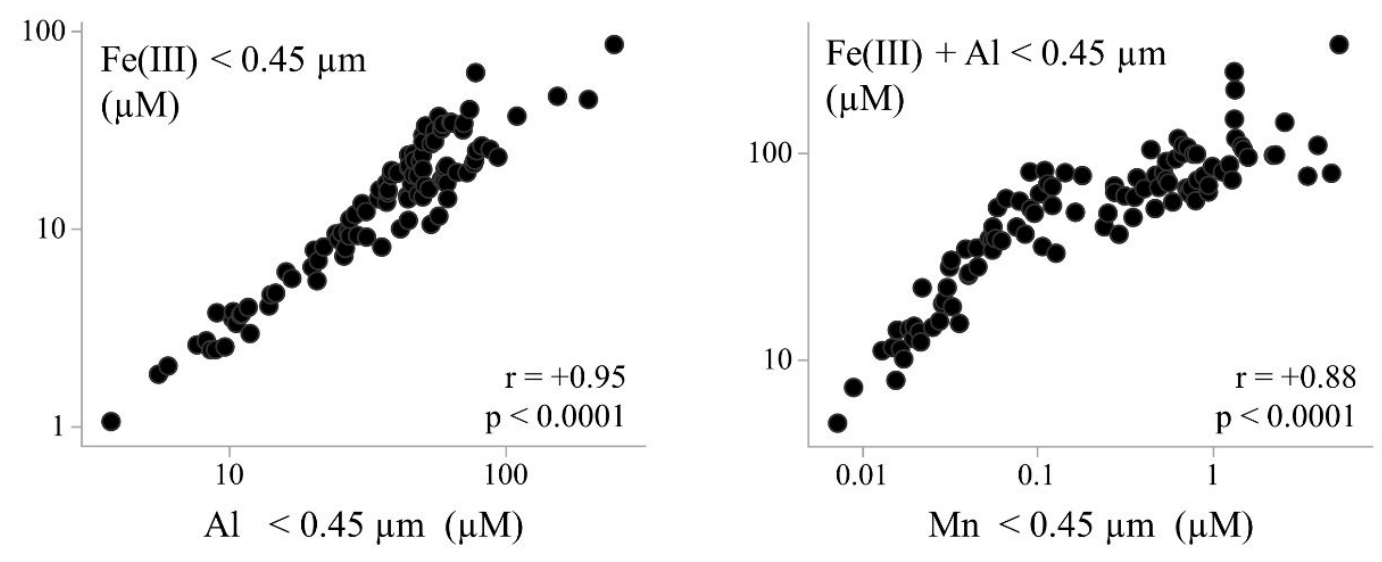

313 Figure S7 The strong correlation between the concentrations of Fe(III) and Al suggests that colloidal Fe(III) and Al particles are present

314 (left). The right panel shows that the sum of the concentrations of Fe(III) and $\mathrm{Al}$ are strongly associated with those of Mn (middle panel). 


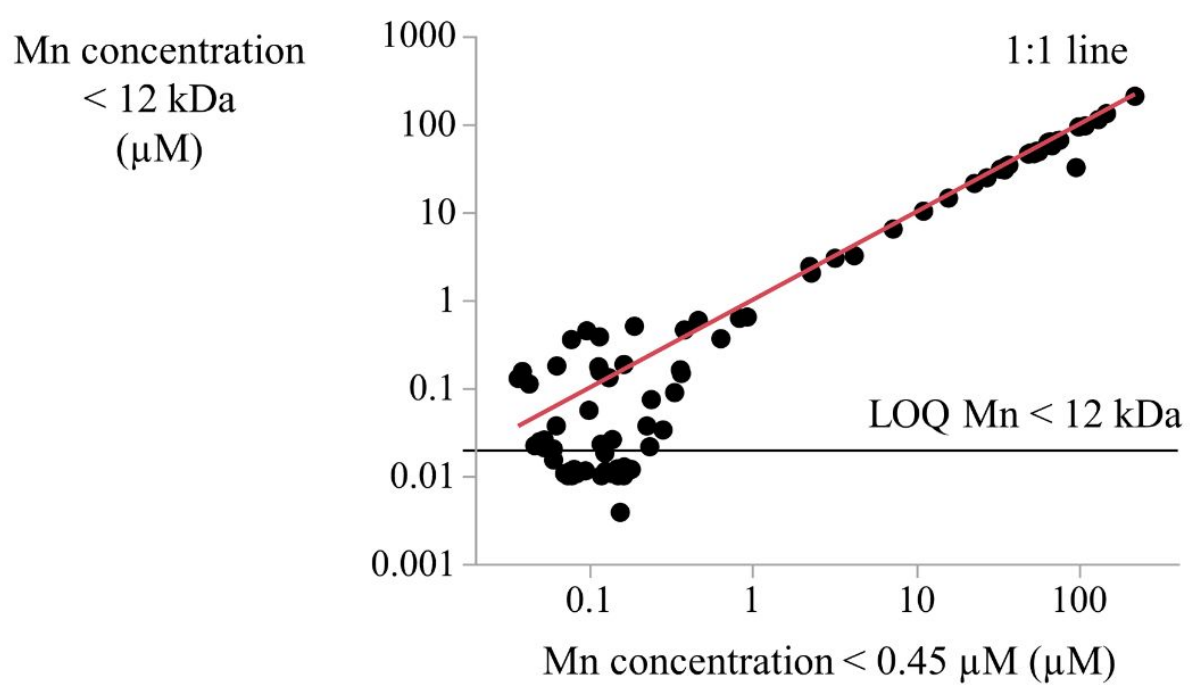

Figure S8 All $0.45-\mu \mathrm{m}$-filterable Mn also passes through 10-12 kDa dialysis membranes for the suspensions sampled during the waterlogged soil incubations and starting from $0.45-\mu \mathrm{m}$-filterable concentrations of $0.4 \mu \mathrm{M}$. Below $0.4 \mu \mathrm{M}$, colloidal $(<0.45 \mu \mathrm{m}$; $>12$ $\mathrm{kDa}) \mathrm{Mn}$ entities might be present. However, uncertainty is increasing as shown by increased deviations from the $1: 1$ line, both above and below the 1:1 line (red). The horizontal black line indicates the limit of quantification (LOQ) for truly dissolved Mn (i.e. $<12 \mathrm{kDa}$ ): $320 \quad 0.02 \mu \mathrm{M}$. 
322 Table S8 The concentrations of solutes (P, Fe, Al, Mn) measured in the wick samplers are well below the corresponding values in the

$3231 \mathrm{mM} \mathrm{CaCl}_{2}$ extracts of field moist soils, collected at the same depth as the wicks. This is attributed to artificial oxidation and colloid

324 retention in the wicks.

\begin{tabular}{|c|c|c|c|c|c|c|c|c|c|c|c|c|}
\hline \multirow{2}{*}{ Treatment } & \multirow{2}{*}{$\begin{array}{c}\text { Depth } \\
\text { (cm) }\end{array}$} & \multicolumn{5}{|c|}{$\mathrm{CaCl}_{2}$ extraction (soil sampled 01/03/2018) } & \multirow{2}{*}{$\begin{array}{c}\text { Depth } \\
\text { (cm) }\end{array}$} & \multicolumn{5}{|c|}{ Wick samples (sampled at $06 / 03 / 2018$ ) } \\
\hline & & $\begin{array}{c}{[\mathrm{P}]} \\
(\mu \mathrm{M}) \\
\end{array}$ & $\begin{array}{c}{[\mathrm{Fe}]} \\
(\mu \mathrm{M}) \\
\end{array}$ & $\begin{array}{c}{[\mathrm{Al}]} \\
(\mu \mathrm{M})\end{array}$ & $\begin{array}{l}{[\mathrm{Mn}]} \\
(\mu \mathrm{M}) \\
\end{array}$ & $\begin{array}{c}{[\mathrm{Ca}]} \\
(\mathrm{mM})\end{array}$ & & $\begin{array}{c}{[\mathrm{P}]} \\
(\mu \mathrm{M}) \\
\end{array}$ & $\begin{array}{c}{[\mathrm{Fe}]} \\
(\mu \mathrm{M}) \\
\end{array}$ & $\begin{array}{c}{[\mathrm{Al}]} \\
(\mu \mathrm{M})\end{array}$ & $\begin{array}{l}{[\mathrm{Mn}]} \\
(\mu \mathrm{M})\end{array}$ & $\begin{array}{c}{[\mathrm{Ca}]} \\
(\mathrm{mM}) \\
\end{array}$ \\
\hline \multirow{2}{*}{ MIN N } & $35-45$ & 4.5 & 16 & 69 & 0.43 & 1.1 & 45 & 0.8 & 0.7 & 1.8 & 0.03 & 1.0 \\
\hline & $90-100$ & 0.2 & 3 & 11 & 0.02 & 1.0 & 100 & 0.3 & 1.0 & 2.9 & 0.06 & 1.2 \\
\hline \multirow{2}{*}{ MSW } & $35-45$ & 6.7 & 26 & 52 & 1.05 & 1.3 & 45 & 0.5 & 1.1 & 0.2 & 0.02 & 2.1 \\
\hline & $90-100$ & 0.6 & 17 & 36 & 0.06 & 1.0 & 100 & 0.2 & 0.0 & $<0.074$ & 0.01 & 2.5 \\
\hline \multirow{2}{*}{ FYM } & $35-45$ & 28.5 & 52 & 126 & 2.98 & 1.1 & 45 & 0.5 & 0.1 & 0.2 & 0.02 & 1.9 \\
\hline & $90-100$ & 0.5 & 14 & 37 & 0.06 & 1.0 & 100 & 0.2 & 0.0 & 0.1 & 0.07 & 2.2 \\
\hline \multirow{2}{*}{$\mathrm{BIO}$} & $35-45$ & 13.3 & 31 & 107 & 2.00 & 1.2 & 45 & 0.4 & 0.0 & 0.1 & 0.01 & 1.8 \\
\hline & $90-100$ & 0.3 & 5 & 15 & 0.03 & 1.0 & 100 & 0.2 & 0.1 & 0.1 & 0.07 & 2.2 \\
\hline \multirow{2}{*}{ GWS } & $35-45$ & 25.8 & 38 & 57 & 1.47 & 1.1 & 45 & 0.9 & 0.1 & 0.2 & 0.01 & 2.2 \\
\hline & $90-100$ & 0.3 & 3 & 8 & 0.02 & 1.2 & 100 & 0.2 & 0.3 & 0.7 & 0.01 & 2.0 \\
\hline
\end{tabular}




\section{REFERENCES}

(1) Cambier, P.; Pot, V.; Mercier, V.; Michaud, A.; Benoit, P.; Revallier, A.; Houot, S. Impact of Long-Term Organic Residue Recycling in Agriculture on Soil Solution Composition and Trace Metal Leaching in Soils. Sci. Total Environ. 2014, 499, 560-573. https://doi.org/10.1016/j.scitotenv.2014.06.105.

(2) Vanden Nest, T.; Ruysschaert, G.; Vandecasteele, B.; Houot, S.; Baken, S.; Smolders, E.; Cougnon, M.; Reheul, D.; Merckx, R. The Long Term Use of Farmyard Manure and Compost: Effects on P Availability, Orthophosphate Sorption Strength and P Leaching. Agric. Ecosyst. Environ. 2016, 216, 23-33. https://doi.org/10.1016/j.agee.2015.09.009.

(3) Noirot-Cosson, P. E.; Vaudour, E.; Gilliot, J. M.; Gabrielle, B.; Houot, S. Modelling the Long-Term Effect of Urban Waste Compost Applications on Carbon and Nitrogen Dynamics in Temperate Cropland. Soil Biol. Biochem. 2016, 94, 138-153. https://doi.org/10.1016/j.soilbio.2015.11.014.

(4) Chalhoub, M.; Garnier, P.; Coquet, Y.; Mary, B.; Lafolie, F.; Houot, S. Increased Nitrogen Availability in Soil after Repeated Compost Applications: Use of the PASTIS Model to Separate Short and Long-Term Effects. Soil Biol. Biochem. 2013, 65, 144-157. https://doi.org/10.1016/j.soilbio.2013.05.023.

(5) Viollier, E.; Inglett, P. W.; Hunter, K.; Roychoudhury, A. N.; Van Cappellen, P. The Ferrozine Method Revisited: Fe (II)/Fe (III) Determination in Natural Waters. Appl. Geochemistry 2000, 15 (6), 785-790. https://doi.org/10.1016/S0883-2927(99)00097-9.

(6) Borch, T.; Kretzschmar, R.; Skappler, A.; Van Cappellen, P.; Ginder-Vogel, M.; Voegelin, 
A.; Campbell, K. Biogeochemical Redox Processes and Their Impact on Contaminant Dynamics. Environ. Sci. Technol. 2010, 44 (1), 15-23. https://doi.org/10.1021/es9026248.

(6) Klysubun, W.; Sombunchoo, P.; Deenan, W.; Kongmark, C. Performance and status of beamline BL8 at SLRI for X-ray absorption spectroscopy. $J$. Synchrotron Rad. 2012, 19(6), 930-936.

(7) Eriksson, A.K.; Hillier, S.; Hesterberg, D.; Klysubun, W.; Ulén, B.; Gustafsson, J.P. Evolution of phosphorus speciation with depth in an agricultural soil profile. Geoderma 2016, 280, 29-37.

(8) Eriksson, A.K.; Hesterberg, D.; Klysubun, W.; Gustafsson, J.P. Phosphorus dynamics in Swedish agricultural soils as influenced by fertilization and mineralogical properties: insights gained from batch experiments and XANES spectroscopy. Sci. Total Environ. 2016, 566-567, 1410-1419.

(9) Ravel, B.; Newville, M. ATHENA, ARTEMIS, HEPHAESTUS: data analysis for X-ray absorption spectroscopy using IFEFFIT. J. Synchrotron Rad. 2005, 12(4), 537-541.

(10) Tannazi, F.; Bunker, G. Determination of chemical speciation by XAFS. Physica Scripta, $2005,115,4$.

(11) Ravel, B. Athena: A User's Guide. Web: https://bruceravel.github.io/demeter/documents/Athena/index.html (last accessed 5 June 2019)

(12) Liu, Y.T.; Hesterberg, D. Phosphate bonding on noncrystalline Al/Fe-hydroxide coprecipitates. Environ. Sci. Technol. 2011, 45, 6283-6289. 